Check for updates

Cite this: Chem. Sci., 2019, 10, 5893

๑ All publication charges for this article have been paid for by the Royal Society of Chemistry

Received 21st April 2019

Accepted 6th May 2019

DOI: $10.1039 / c 9 s c 01978 b$

rsc.li/chemical-science

\title{
Photoelectric effect accelerated electrochemical corrosion and nanoimprint processes on gallium arsenide wafers
}

\author{
Chengxin Guo, ${ }^{a}$ Lin Zhang, ${ }^{a}$ Matthew M. Sartin, ${ }^{a}$ Lianhuan Han, ${ }^{\text {tb }}$ Zhao-Wu Tian, ${ }^{a}$ \\ Zhong-Qun Tian (D) and Dongping Zhan (D)*a
}

\begin{abstract}
Here we report photoelectric-effect-enhanced interfacial charge transfer reactions. The electrochemical corrosion rate of $n$-type gallium arsenide ( $\mathrm{n}-\mathrm{GaAs}$ ) induced by the contact potential at platinum (Pt) and GaAs boundaries can be accelerated by the photoelectric effect of $n$-GaAs. When a GaAs wafer is illuminated with a xenon light source, the electrons in the valence band of GaAs will be excited to the conduction band and then move to the Pt boundaries due to the different work functions of the two materials. This results in an enhanced contact electric field as well as an enlarged Pt/GaAs contact potential. Consequently, in the presence of electrolyte solution, the polarizations of both the Pt/solution interface and the GaAs/solution interface at the Pt/GaAs/solution 3-phase boundary are enhanced. If the accumulated electrons on the Pt side are removed by electron acceptors in the solution, anodic corrosion of GaAs will be accelerated strictly along the Pt/GaAs/solution 3-phase boundary. This photoenhanced electrochemical phenomenon can increase the corrosion rate of GaAs and accelerate the process of electrochemical nanoimprint lithography (ECNL) on GaAs. The method opens an innovative, highly efficient, low-cost nanoimprint technique performed directly on semiconductors, and it has prospective applications in the semiconductor industry.
\end{abstract}

\section{Introduction}

Electrochemical corrosion is an electrochemical reaction which occurs spontaneously in a "short-circuit" electrolytic microcell. ${ }^{1-4}$ It is reported that one third of the world's steel products are corroded each year. ${ }^{5}$ Therefore, a significant effort has been made to develop anti-corrosion technology. On the other hand, corrosion plays an important role in the fabrication of three dimensional micro-nano structures (3D-MNSs) acting as sensors and actuators in microelectromechanical systems (MEMSs) and miniaturized total analysis systems ( $\mu$-TASs). Once corrosion processes are well controlled, these could become a competitive template-forming method for the fabrication of 3D MNSs. ${ }^{6,7}$

The original motivation for template forming based on chemical principles is to make large-area 3D-MNSs directly on semiconductor wafers, which is difficult for photolithography and nanoimprint lithography (NIL). ${ }^{8,9}$ Derived from the

\footnotetext{
${ }^{a}$ State Key Laboratory of Physical Chemistry of Solid Surfaces (PCOSS), Collaborative Innovation Center of Chemistry for Energy Materials (iChEM), Engineering Research Center of Electrochemical Technologies of Ministry of Education, Department of Chemistry, College of Chemistry and Chemical Engineering, Xiamen University, Xiamen 361005, China. E-mail: dpzhan@xmu.edu.cn

${ }^{b}$ Department of Mechanical and Electrical Engineering, School of Aerospace Engineering, Xiamen University, Xiamen 361005, China
}

mechanical extrusion-forming technique, NIL is considered to be one of the most competitive template-forming microfabrication methods, with high resolution and low cost. ${ }^{10}$ In general, NIL involves thermoplastic or photocuring resists, which are filled into NIL templates with 3D-MNSs. After demoulding, the 3D-MNSs in the NIL template left in the resists are transferred to functional materials by subsequent technical processes, e.g. , physical or chemical etching. ${ }^{11-16}$ In 2002 laserassisted direct imprint (LADI) was proposed to fabricate 3DMNSs on a silicon (Si) wafer. An extremely powerful laser pulse was introduced through a quartz imprint template to melt the Si surface. Simultaneously, high pressure was applied to press the 3D-MNSs into the molten Si surface. ${ }^{17}$ LADI is very costly, because the laser light source is very expensive and semiconductor wafers are fragile. Direct nanoimprint on semiconductors has seldom been reported since then. Compared to physical methods, template forming methods based on chemical principles are a reasonable choice.

For years we have been engaged in the study of the confined etchant layer technique (CELT) to fabricate functional 3D-MNSs on various semiconductor wafers, where the electrogenerated etchant is confined in a diffusion layer at the micro-nano meter scale. ${ }^{18-20}$ To avoid the alignment problem of CELT, we recently proposed electrochemical nanoimprint lithography (ECNL) based on contact-potential-induced corrosion. ${ }^{21-23}$ We found that, when a platinum $(\mathrm{Pt})$ metalized template contacts $\mathrm{Si}$ or 
gallium arsenide (GaAs), a contact potential will be established at the Pt/GaAs boundary, due to the different electronic work functions of the two materials. In the presence of electrolyte solution with electron acceptors, the excess electrons at the Pt side will be transferred across the Pt/solution interface, and the $\mathrm{Si}$ or GaAs/solution interface will be polarized and corroded by the accumulated holes strictly along the Pt/semiconductor/ solution 3-phase boundaries. Compared with NIL, ECNL works directly on the semiconductor wafer, without any resists or auxiliary processes. The machining accuracy of ECNL is lower than the Debye length of the space charge layer across the Pt/ semiconductor boundaries, which means that it is indeed spatially confined corrosion at the micro-nanometer scale.

Here we report that contact-potential-induced corrosion can be accelerated because of the photoelectric effect of the semiconductor substrate. The photo illumination can increase the contact potential between the $\mathrm{Pt} / \mathrm{GaAs}$ boundaries and thus, enhance the polarization of both the GaAs/solution interface and the $\mathrm{Pt} /$ solution interface, resulting in an accelerated anodic dissolution of GaAs. Based on this principle, we demonstrate that the efficiency of ECNL can be promoted by the photoenhanced electrochemical mechanism.

\section{Results and discussion}

When GaAs contacts Pt, electrons will move from n-GaAs to Pt until the Fermi levels of both are equal to one another, because the electron work function of n-GaAs is lower than that of Pt. Consequently, a contact electric field, as well as a contact potential, will be established at the Pt/n-GaAs boundary, in which the Pt side is negatively charged, and the n-GaAs side is positively charged. We have demonstrated that the contact potential can induce the anodic dissolution of n-GaAs (Fig. 1a) when the system is immersed in an electrolyte with electron acceptors (e.g., $\mathrm{KMnO}_{4}{ }^{-}$), and we developed an ECNL technique for the template forming of 3D-MNSs. We realized that n-GaAs is a semiconductor with excellent photoelectric properties. As shown in Fig. 1b, when n-GaAs is illuminated, the electrons will be exited from the valence band to the conduction band, and they will then move to the Pt side, due to the difference in the work functions of the two materials. The system will equilibrate when both materials have the same Fermi level at the Pt/n-GaAs boundary, i.e., to establish thermodynamic equilibrium. The contact potential will be enlarged and the polarizations of both the $n-G a A s / s o l u t i o n$ interface and the Pt/solution interface will be enhanced. Since the kinetic rate of $\mathrm{MnO}_{4}{ }^{-}$reduction on the Pt surface is much higher, the polarization of the GaAs/solution interface will be enhanced, and the anodic corrosion of n-GaAs will be accelerated as depicted in Fig. 1c.

The above theoretical analysis is demonstrated experimentally by measurements of interfacial potential in the presence of electrolyte solution with $40 \mathrm{mM} \mathrm{KMnO}_{4}$ and $1.84 \mathrm{M} \mathrm{H}_{2} \mathrm{SO}_{4}$. We used a bipotentiostat to monitor the potentials of both the $\mathrm{Pt} /$ GaAs interface and the GaAs/solution interface at the same time. As shown in Fig. 1d, when the Pt-metalized template electrode is separated from the GaAs wafer, the potentials of the $\mathrm{Pt} / \mathrm{GaAs}$ interface and GaAs/solution interface are measured to

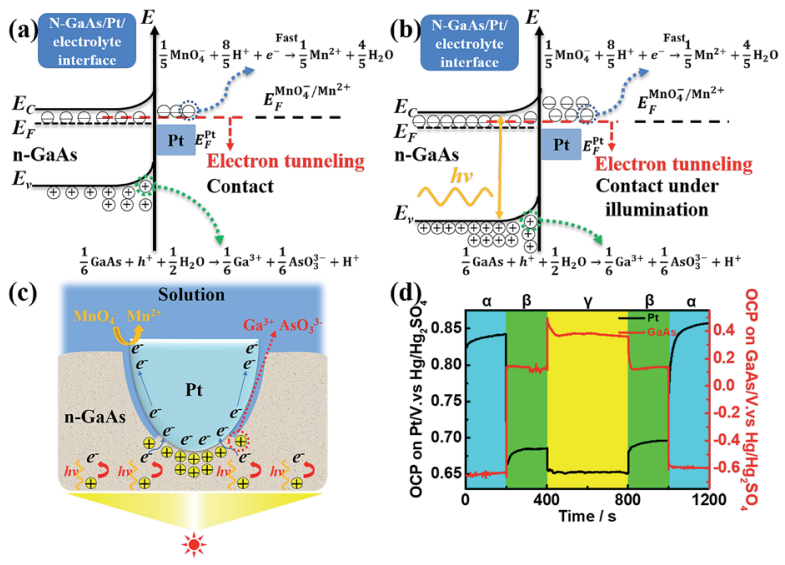

Fig. 1 (a) The principle of contact-potential-induced corrosion of $n$ GaAs. (b) The principle of contact-potential-induced corrosion of $n$ GaAs enhanced by the photoelectric effect. (c) The schematic diagram of the photoelectric effect accelerated ECNL processes on an n-GaAs wafer. (d) The potential measurements of the Pt/solution interface (black line) and the $n$-GaAs/solution interface (red line). The $\alpha, \beta$, and $\gamma$ regions correspond to the case where the $\mathrm{n}$-GaAs wafer and the $\mathrm{Pt}$ template are separated, contacted without illumination, and contacted with illumination.

be $0.84 \mathrm{~V}$ and $-0.65 \mathrm{~V}$, respectively $v s$. the $\mathrm{Hg} / \mathrm{Hg}_{2} \mathrm{SO}_{4}$ reference electrode. When the materials came in contact with each other under a pressure of $0.5 \mathrm{~atm}$, the potential of the $\mathrm{Pt} / \mathrm{solution}$ interface quickly steps to $0.66 \mathrm{~V}$ and finally stabilizes at $0.68 \mathrm{~V}$. Meanwhile, the potential of the GaAs/solution interface increases to $0.13 \mathrm{~V}$, and finally stabilizes at $0.14 \mathrm{~V}$ after a transient time. Furthermore, when the back of the GaAs wafer is illuminated with a xenon light source (output power: $460 \mathrm{~mW}$ ), the potential of the $\mathrm{Pt} /$ solution interface decreases from $0.68 \mathrm{~V}$ to $0.65 \mathrm{~V}$, and the potential of the GaAs/solution interface increases from $0.13 \mathrm{~V}$ to $0.49 \mathrm{~V}$, before stabilizing at $0.38 \mathrm{~V}$. The observed transient state of the GaAs/solution interface from $0.49 \mathrm{~V}$ to $0.38 \mathrm{~V}$ indicates the establishment of a new thermodynamic equilibrium caused by photo-illumination. All the results show that the photoelectric effect will enhance the polarization of both the Pt/solution interface and the GaAs/ solution interface. The processes are very reversible when light illumination is stopped and when the Pt template is separated from the GaAs wafer (Fig. 1d).

How does the photoelectric-effect-enhanced polarization affect the interfacial charge transfer reaction? Linear scan voltammetry experiments were performed separately using the $\mathrm{Pt}$ electrode and the GaAs electrode without and with illumination in the same electrolyte solution. The area of the n-GaAs electrode and Pt disk electrode is $1.5 \mathrm{~cm}^{2}$ and $0.0314 \mathrm{~cm}^{2}$, respectively. As shown in Fig. 2a and b, the apparent anodic current density on the GaAs electrode is about $6.7 \mu \mathrm{A} \mathrm{cm}{ }^{-2}$ without illumination and increases to more than $77.9 \mu \mathrm{A} \mathrm{cm}{ }^{-2}$ with illumination. The current density change on the Pt electrode is not so dramatic, but it is still much higher than that obtained on the GaAs electrode (Fig. 2c and d). Fig. 3 and Table 1 show the Tafel experiments and the calculated kinetic parameters, indicating that the exchange current density $\left(i^{0}\right)$ of the anodic 
(a)

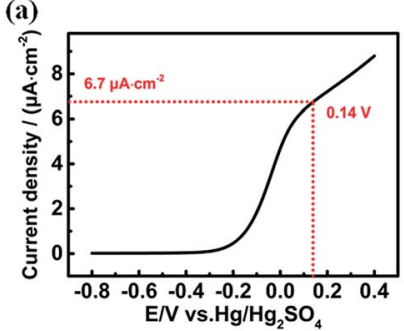

(c)

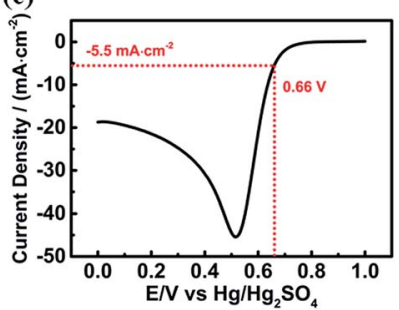

(b)

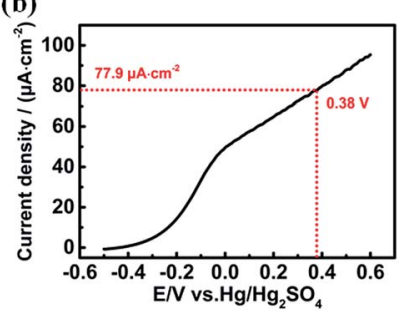

(d)

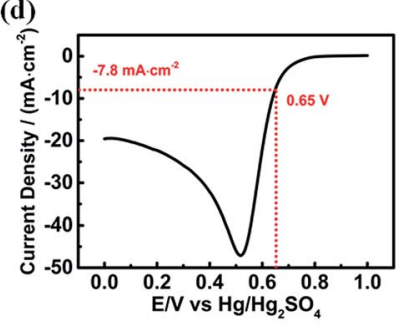

Fig. 2 Linear scan voltammograms of the $\mathrm{n}-\mathrm{GaAs}$ electrode and Pt electrode at a scan rate of $100 \mathrm{mV} \mathrm{s}^{-1}$ : (a) and (c) in the dark; (b) and (d) under illumination. The aqueous solution contains $40 \mathrm{mM} \mathrm{KMnO}_{4}$ and $1.84 \mathrm{M} \mathrm{H}_{2} \mathrm{SO}_{4}$. The working temperature is kept at $25^{\circ} \mathrm{C}$ and the illumination power is $460 \mathrm{~mW}$.
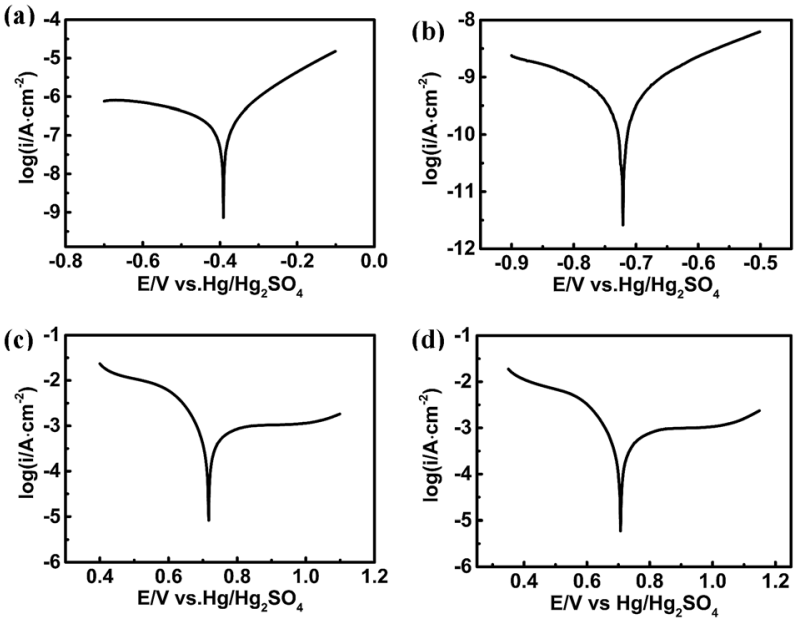

Fig. 3 (a), (b) Tafel curves measured on an n-GaAs electrode with and without illumination. (c), (d) Tafel curves measured on a Pt disk electrode with and without illumination. The aqueous solution contains $40 \mathrm{mM} \mathrm{KMnO}_{4}$ and $1.84 \mathrm{M} \mathrm{H}_{2} \mathrm{SO}_{4}$. The working temperature is kept at $25^{\circ} \mathrm{C}$ and the illumination power is $460 \mathrm{~mW}$.

corrosion of GaAs increases from $\left(6.42 \times 10^{-10}\right) \mathrm{A} \mathrm{cm}^{-2}$, in the dark, to $\left(2.68 \times 10^{-7}\right) \mathrm{A} \mathrm{cm}^{-2}$, under illumination. However, the $i^{0}$ of $\mathrm{MnO}_{4}{ }^{-}$reduction on the Pt electrode increases from (5.16 $\left.\times 10^{-4}\right) \mathrm{A} \mathrm{cm}^{-2}$, in the dark, to $\left(7.42 \times 10^{-4}\right) \mathrm{A} \mathrm{cm}^{-2}$, under illumination. From the $i^{0}$ values, it can be concluded that the cathodic reduction rate of $\mathrm{MnO}_{4}{ }^{-}$on the $\mathrm{Pt}$ electrode is still much higher than the anodic corrosion rate of GaAs even under illumination. The rate-determining step of the reaction system is the corrosion of GaAs, regardless of whether or not the system is illuminated. It should be noted that the corrosion rate of GaAs is promoted by about three orders of magnitude by the photoelectric effect, which indicates acceleration of the ECNL processes and thus an improvement of its fabrication efficiency.

Comparison ECNL experiments were performed with and without illumination. Fig. $4 \mathrm{a}$ and b show a concave microlens array fabricated by ECNL on a GaAs wafer for a working time of 20 minutes, without and with an illumination power of 460 $\mathrm{mW}$. From the profiles shown in Fig. $4 \mathrm{c}$, it can be seen that the removal rate with illumination is accelerated by more than (a)

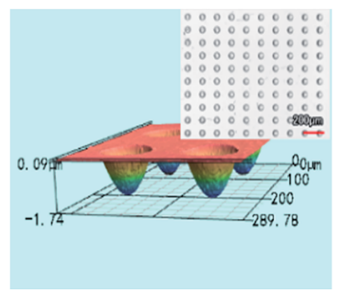

(c)

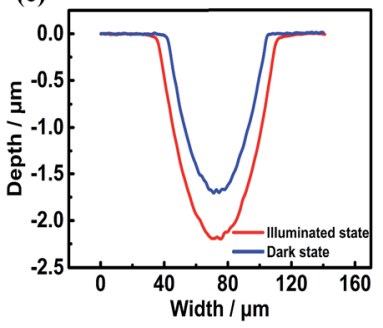

(b)

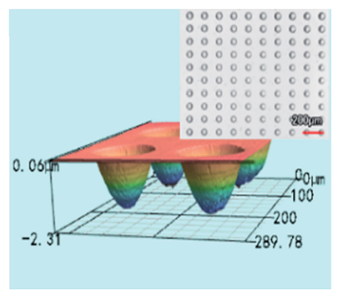

(d)

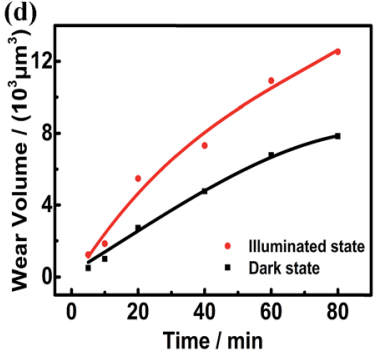

Fig. 4 Confocal laser scanning microscope images of structures on $n-$ GaAs fabricated by electrochemical nanoimprint lithography (a) in the dark and (b) under illumination. (c) Comparison of cross-sectional profiles of structures on $n$-GaAs fabricated under illumination and in the dark. The time is 20 minutes. (d) Relationship between the imprint time and the wear volumes under illumination and in the dark. The aqueous solution contains $40 \mathrm{mM} \mathrm{KMnO}_{4}$ and $1.84 \mathrm{M} \mathrm{H}_{2} \mathrm{SO}_{4}$. The working temperature is kept at $25^{\circ} \mathrm{C}$ and the illumination power is 460 $\mathrm{mW}$.

Table 1 Apparent kinetic parameters from Tafel experiments ${ }^{a}$

\begin{tabular}{|c|c|c|c|c|c|}
\hline & $E_{\text {corr }}(\mathrm{V})$ & $i_{\text {corr }}\left(\mathrm{A} \mathrm{cm}^{-2}\right)$ & Slope & $\alpha n$ & $i^{0}\left(\mathrm{~A} \mathrm{~cm}^{-2}\right)$ \\
\hline GaAs-dark & -0.714 & $6.87 \times 10^{-10}$ & 0.217 & 0.272 & $6.42 \times 10^{-10}$ \\
\hline GaAs-illuminated & -0.394 & $2.68 \times 10^{-7}$ & 0.159 & 0.372 & $2.68 \times 10^{-7}$ \\
\hline Pt-illuminated & 0.729 & $7.44 \times 10^{-4}$ & -0.138 & 0.429 & $7.42 \times 10^{-4}$ \\
\hline
\end{tabular}

${ }^{a} E_{\text {corr }}$ is the corrosion potential, $i_{\text {corr }}$ is the corrosion current density, $\alpha$ is the charge transfer coefficient, $n$ is the number of transferred electrons and $i^{0}$ is the exchange current density. 
a factor of 1.5. The dependence of the removal amount on the corrosion time is shown in Fig. 4d. The removal rate will increase rapidly at the beginning and then slow down. Fig. 5a and $b$ show the microlens profiles and removal amount at different illumination powers within 15 minutes. The removal rate (or volume) is improved when the illumination power is higher than $150 \mathrm{~mW}$. This threshold value is actually the balance between the charge separation, recombination, and transport in the n-GaAs wafer, and also the interfacial charge transfer processes involved in ECNL. The removal rate increases linearly with illumination power when the power is higher than the threshold value.

From the Tafel experiments performed in the bulk solution with isolated n-GaAs electrodes, we know that the corrosion rate is enhanced by three orders of magnitude with illumination. However, the removal rate of ECNL is not promoted so fast. Indeed, the ECNL system is an isolated, thin-layer electrolytic cell. The rapid consumption of $\mathrm{MnO}_{4}{ }^{-}$anions creates a serious mass balance problem. The decrease of $\mathrm{MnO}_{4}{ }^{-}$concentration will slow down the electron transfer rate on the $\mathrm{Pt}$ side. According to the electroneutrality principle, the corrosion rate of $\mathrm{n}$-GaAs by holes will decrease. Although the reduction of $\mathrm{MnO}_{4}{ }^{-}$anions on the $\mathrm{Pt}$ electrode is $\mathrm{pH}$-dependent, the consumption of protons will not hinder the electron transfer path, because the proton concentration is more than 90 times higher than that of $\mathrm{MnO}_{4}{ }^{-}$anions.

\section{Experimental}

\section{Chemicals and materials}

All the chemicals were of analytical grade or better. Potassium permanganate $\left(\mathrm{KMnO}_{4}\right)$, sulfuric acid $\left(\mathrm{H}_{2} \mathrm{SO}_{4}\right)$, ferrous sulfate $\left(\mathrm{FeSO}_{4} \cdot 7 \mathrm{H}_{2} \mathrm{O}\right)$, hydrogen peroxide $\left(\mathrm{H}_{2} \mathrm{O}_{2}\right)$, ethanol, and acetone were provided by Sinopharm, China. Silicon-doped n-GaAs (100) wafers with a doping level between $(0.8-2.3) \times 10^{18}$
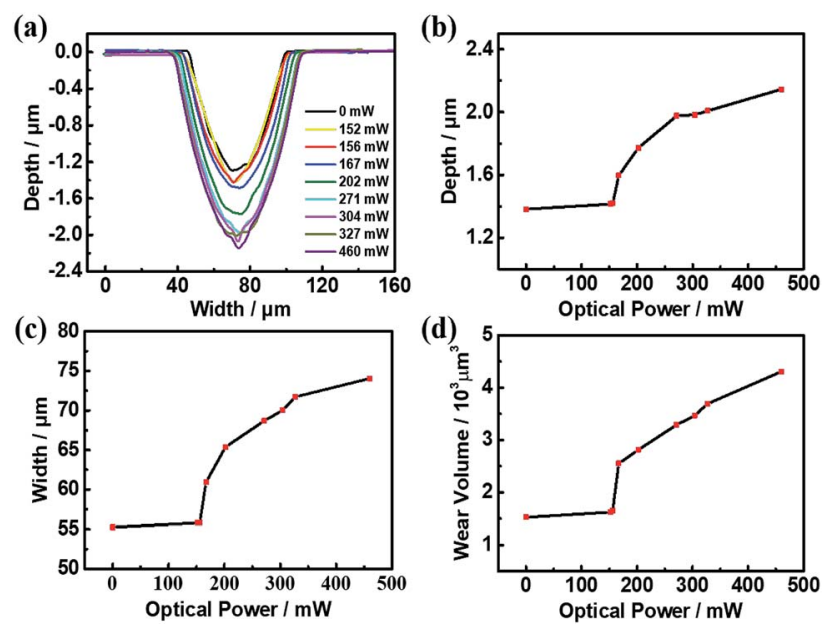

Fig. 5 (a) Cross-sectional profiles, (b) depths, (c) widths, and (d) removal volumes of the concave microlens fabricated on an n-GaAs wafer under different illumination powers. The imprint time is 15 minutes, and the aqueous solution contains $40 \mathrm{mM} \mathrm{KMnO}_{4}$ and $1.84 \mathrm{M}$ $\mathrm{H}_{2} \mathrm{SO}_{4}$ $\mathrm{cm}^{-3}$ were purchased from China Crystal Technologies Co., China. Before the experiments, the n-GaAs wafers were rinsed with acetone, ethanol, and deionized water. The platinum (purity: 99.95\%) and titanium (purity: 99.95\%) sputtering targets used for the preparation of the ECNL template were provided by the Beijing Cuibolin Nonferrous Metals Institute. All aqueous solutions were prepared with deionized water (18.2 $\mathrm{M} \Omega \mathrm{cm}$, Milli-Q, Millipore Co.).

\section{Electrochemical measurements}

A CHI 920 electrochemical workstation (CH Instrument Co., USA) was adopted to measure the interfacial potentials and the Tafel behaviors of the ECNL system with and without illumination. In these measurements, an $\mathrm{Hg} / \mathrm{Hg}_{2} \mathrm{SO}_{4}$ reference electrode and a platinum plate electrode (area: $1 \mathrm{~cm}^{2}$ ) were used as the reference electrode and the counter electrode, respectively.

\section{ECNL experiments}

The imprint template (area: $0.385 \mathrm{~cm}^{2}$ ) is made of polymethyl methacrylate (PMMA) with a convex hemisphere microlens array (diameter: $140 \mathrm{~nm}$ ) therein. The template was cleaned with oxygen plasma and then coated with titanium (thickness: $10 \mathrm{~nm}$ ) and platinum (thickness: $100 \mathrm{~nm}$ ) by magnetron sputtering. The ECNL experiments were performed using a nanoimprint equipment (Eitre-6, Obducat Technologies AB, Sweden) as reported in our previous work, ${ }^{23}$ where a special electrolytic cell is adapted to hold the ECNL system. The working solution contained $40 \mathrm{mM} \mathrm{KMnO}$ and $1.84 \mathrm{M} \mathrm{H}_{2} \mathrm{SO}_{4}$. The contact pressure was fixed at 0.5 atm between the template electrode and the workpiece, and it was monitored by using a force sensor during the ECNL process. After the experiments, the workpiece was rinsed with deionized water and dried under nitrogen for further characterization, and the template was rinsed with $0.5 \mathrm{M} \mathrm{FeSO}_{4}$ and $1.84 \mathrm{M} \mathrm{H}_{2} \mathrm{SO}_{4}$ to remove the residual manganese dioxide $\left(\mathrm{MnO}_{2}\right)$ for reuse. A homemade illumination system with a xenon light source (LSP-X500, Zolix Co., Beijing) was used to perform the photo-illumination-accelerated ECNL experiments (Fig. 6). The reaction cell is kept at a constant temperature with a thermostatic water bath during the ECNL fabrication.

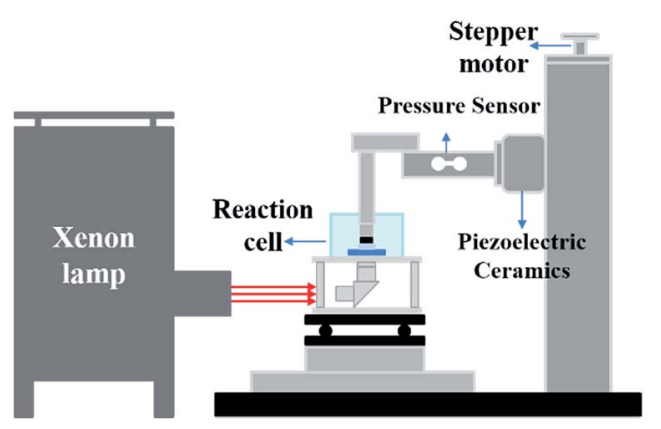

Fig. 6 Schematic diagram of the photoelectric-effect-accelerated ECNL instrument. 


\section{Characterization}

An optical microscope (Olympus K-100, Olympus Co., Japan) was employed to observe the status of the template and the fabricated workpiece. A confocal laser microscopy setup (VK$\mathrm{X} 250$, Keyence Co.) was employed to characterize the morphology and the profile of the imprinted 3D-MNSs in the semiconductors.

\section{Conclusions}

We demonstrated photoelectric-effect-accelerated corrosion of GaAs induced by the contact potential between Pt and GaAs boundaries in an electrolyte environment. Under illumination of a xenon light source, electrons will be excited from the valence band to the conduction band and then move to the Pt side because of their different electronic work functions. Thus, the polarization of both the Pt/solution interface and the GaAs/ solution interface is enhanced, and the interfacial charge transfer is accelerated kinetically. Kinetic investigations show that the rate-determining step is indeed the corrosion of GaAs. However, in practical ECNL processes, the mass balance of $\mathrm{MnO}_{4}{ }^{-}$anions and the removal of the products will cause a problem. The accelerated corrosion rate of GaAs will improve the ECNL efficiency. This unique electrochemical phenomenon makes ECNL more competitive as a microfabrication technique for functional 3D-MNSs directly on semiconductor wafers and has a prospective application in the semiconductor industry.

\section{Conflicts of interest}

C. Guo and L. Zhang contributed equally. There are no conflicts to declare.

\section{Acknowledgements}

The financial support from the National Natural Science Foundation of China (NSFC 21827802, 21573054 and 21621091) is appreciated.

\section{Notes and references}

1 D. W. Deberry, J. Electrochem. Soc., 1985, 132, 1022-1026.

2 M. Pourbaix, Biomaterials, 1984, 5, 122-134.
3 L. Liu, Y. Li and F. Wang, J. Mater. Sci. Technol., 2010, 26, 114.

4 X. Liu, J. Xiong, Y. Lv and Y. Zuo, Prog. Org. Coat., 2009, 64, 497-503.

5 T. N. Nguyen, J. B. Hubbard and G. B. McFadden, J. Coatings Technol., 1991, 63, 43-52.

6 D. Zhan, L. Han, J. Zhang, Q. He, Z.-W. Tian and Z.-Q. Tian, Chem. Soc. Rev., 2017, 46, 1526-1544.

7 D. Zhan, L. Han, J. Zhang, K. Shi, J.-Z. Zhou, Z.-W. Tian and Z.-Q. Tian, Acc. Chem. Res., 2016, 49, 2596-2604.

8 S. Y. Chou, P. R. Krauss and P. J. Renstrom, Appl. Phys. Lett., 1995, 67, 3114-3116.

9 L. J. Guo, Adv. Mater., 2007, 19, 495-513.

10 S. Y. Chou, P. R. Krauss and P. J. Renstrom, Science, 1996, 272, 85-87.

11 H. Schift, J. Vacuum Sci. Technol. B, 2008, 26, 458-480.

12 C.-C. Yu and H.-L. Chen, Microelectron. Eng., 2015, 132, 98119.

13 J. K. Hwang, S. Cho, J. M. Dang, E. B. Kwak, K. Song, J. Moon and M. M. Sung, Nat. Nanotechnol., 2010, 5, 742-748.

14 A. Cattoni, P. Ghenuche, A.-M. Haghiri-Gosnet, D. Decanini, J. Chen, J.-L. Pelouard and S. Collin, Nano Lett., 2011, 11, 3557-3563.

15 R. Kawajiri, H. Takagishi, T. Masuda, T. Kaneda, K. Yamazaki, Y. Matsuki, T. Mitania and T. Shimoda, J. Mater. Chem. C, 2016, 4, 3385-3395.

16 T. Masuda, H. Takagishi, K. Yamazaki and T. Shimoda, ACS Appl. Mater. Interfaces, 2016, 8, 9969-9976.

17 S. Y. Chou, K. Chris and G. Jian, Nature, 2002, 417, 835.

18 Z. W. Tian, Z. D. Fen, Z. Q. Tian, X. D. Zhuo, J. Q. Mu, C. Z. Li, H. S. Lin, B. Ren, Z. X. Xie and W. L. Hu, Faraday Discuss., 1992, 94, 37-44.

19 L. Zhang, X.-Z. Ma, J.-L. Zhuang, C.-K. Qiu, C.-L. Du, J. Tang and Z.-W. Tian, Adv. Mater., 2007, 19, 3912-3918.

20 X.-Z. Ma, L. Zhang, G.-H. Cao, Y. Lin and J. Tang, Electrochim. Acta, 2007, 52, 4191-4196.

21 J. Zhang, L. Zhang, L. Han, Z.-W. Tian, Z.-Q. Tian and D. Zhan, Nanoscale, 2017, 9, 7476-7482.

22 J. Zhang, L. Zhang, W. Wang, L. Han, J.-C. Jia, Z.-W. Tian, Z.-Q. Tian and D. Zhan, Chem. Sci., 2017, 8, 2407-2412.

23 L. Zhang, J. Zhang, D. Yuan, L. Han, J.-Z. Zhou, Z.-W. Tian, Z.-Q. Tian and D. Zhan, Electrochem. Commun., 2017, 75, 1-4. 